\title{
Impact of internal heat gain profiles on the design cooling capacity of landscaped offices
}

\author{
Seyed Shahabaldin Seyed Salehi ${ }^{1 *}$, Andrea Ferrantelli ${ }^{1}$, Hans Kristjan Aljas ${ }^{1}$, Jarek Kurnitski ${ }^{2,1,3}$, Martin Thalfeldt $^{2,1}$ \\ ${ }^{1}$ Department of Civil Engineering and Architecture, Tallinn University of Technology, 19086 Tallinn, Estonia \\ ${ }^{2}$ Smart City Center of Excellence, Tallinn University of Technology, 19086 Tallinn, Estonia \\ ${ }^{3}$ Department of Civil Engineering, Aalto University, Aalto, Finland
}

\begin{abstract}
Using passive methods in façade design for controlling heating and cooling needs is an important prerequisite for constructing cost-effective nearly zero-energy buildings. Optimal control of solar heat gains reduces the cooling demand and the size of the active cooling systems. However, applying such methods increases the impact of internal heat gains on the heat balance of the buildings, and accordingly also the dimensions of cooling systems. Therefore, a good model of internal heat gains is needed for a reliable and optimal sizing of the cooling sources. This paper aims to bring understanding to developing internal heat gains models for sizing the cooling systems. For this purpose, several weekly internal heat gain profiles were selected from a large set of tenant-based electricity use measured in 4 office buildings in Tallinn. The selection was based on maximum daily or weekly peak loads of an office space per floor area. The selected profiles and the schedule of EN 16798-1 were used to dimension ideal coolers in the zones of a generic floor model with landscaped offices developed in IDA-ICE 4.8. The model had variable window sizes and thermal mass of the building materials. Finally, the internal heat gains models resulting in the largest cooling capacity were identified. We found that utilizing thermal mass can reduce the cooling system size by up to $7 \%$ on average and the models with big windows and light structure need the largest cooling systems. The cooling loads obtained with the profile of EN 16798-1 did not significantly differ from the average of other profiles' results. This paper focused mainly on the zonal dimensioning of cooling systems, therefore a more in-depth analysis of the different occupancy patterns as well as developing models for dimensioning the cooling system at the building level, is needed.
\end{abstract}

\section{Introduction}

Nearly zero or net-zero energy buildings are increasingly getting attention in recent years. Many countries have already provided regulations while working on road maps to reduce energy usage in the building sector [1]. The major efforts for designing such buildings are passive strategies for reducing cooling and heating demand, implementing systems for utilizing renewable energy sources and using more efficient HVAC (active) systems. In order to reduce heat gains for efficient cooling design, some passive solutions can be used, e.g. controlling heat gain from the sun using shadings, applying natural ventilation, passive façade design, etc [2]. Implementing such methods will reduce the total cooling demand of the building while it increases the impact of internal heat gains on cooling system size [3]. The internal heat gains in total cooling load are important in cold climates but not always in warm climates. In a warm climate for an old building without external wall insulations, Coşkun et al. in [4] indicate a share of internal heat gains in total cooling load as low as around $1 \%$, while the share of electricity use for equipment usage can be up to $60 \%$ of the total electricity use [4]. However, by reducing the internal heat gains from lighting (using efficient LED lights), equipment and small power consumers, majorly laptops and monitors in office buildings, a $60 \%$ reduction in cooling loads can be achieved in certain building systems [3].

There is a long list of influential decisions during the design phase that can affect cooling loads specifically from the passive design perspective. Among them, the parameters related to the windows and the thermal mass of the building parts are focused on in this paper. The optimal window to wall ratio (WWR) has been suggested to be between 0.30 and 0.45 for all sorts of climates and building orientations [5] while considering just extreme cold climates, it is suggested to be around 0.37 or 0.6 depending on the orientation and glazing type [6]. Shadings are also important, Thalfeldt et. al. in [7] indicated that external shadings are effective to reduce cooling size demand up to $70 \%$ while suggesting a specific complex control method to achieve this. The materials that are used to construct a building can store heat and release that heat when there is a temperature difference, no matter if the designers have calculated them or not. Sarbu et al. in [8] listed selected solidliquid materials for sensible heat storage. The most common materials are Water, Wood, Concrete, Cast

* Corresponding author: shahab.salehi@taltech.ee 
iron, Sand, different types of Brick and Rock. On the other hand, there are Phase Change Materials (PCM) that are being used due to latent heat storage potential without temperature change, however, they are not related to this article. In a summary graph, Sarbu et al. [8] indicated selected materials for energy storage purpose that gives the reader an overall understanding. The maximum energy storage capacity of a $10-\mathrm{mm}-$ thick building part operating between 18 and $26{ }^{\circ} \mathrm{C}$ for $24 \mathrm{~h}$ is $18 \mathrm{Wh} / \mathrm{m}^{2}$ for wood while numbers for Concrete and Iron are $48 \mathrm{Wh} / \mathrm{m}^{2}$ and $79 \mathrm{Wh} / \mathrm{m}^{2}$ respectively. The energy storage capacity of the building components/materials can reduce the total energy required for heating and cooling, but another important impact is the so-called "peak shifting" which means that during the cooling load peak periods, the storage can meet a part of the cooling demand to reduce pressure on the active cooling system, which may lead to smaller HVAC system [9].

The procedure of estimating and calculating cooling loads in a zone must contain conductive, convective and radiative heat balance for each surface and a general convective heat balance for the zone. The main calculation method for this procedure is Heat Balance (HB) method. This method solves the problem directly through an iterative procedure in which most often a computer must be involved. However, while ASHRAE suggests Heat Balance as the most accurate method, there are several other methods for cooling load calculation described in the handbook. The Radiant Time Series (RTS) method is a simplified method based on the Heat Balance method. The benefits of the RTS method are not to be iterative and quantifies the contribution of each construction part to the total load which helps practitioners with judgements over different construction parts and zones. Nevertheless, ASHRAE mentions that the RTS method can be used for peak load design and should not be used for annual energy simulations due to its limiting assumptions. Some other methods are also accepted by ASHRAE to be used such as transfer function method (TFM), cooling load temperature difference/ cooling load factor (CLTD/CLF) method, total equivalent temperature difference/time averaging (TETDA/TA) method, but since RTS can be effectively replaced with all other methods, they are rarely used. [10]

The impact of occupants' behavior on energy consumption and HVAC design in the buildings gained attention in the late 1950's with a focus on window openings and ventilation systems. This attention turned to occupants' behavior relation with energy consumption in the 80 's. A very informative chronological review of major methods for occupants' behavior modeling is done by Tam et. al. [11]. Zhao defined occupants as "active" and "passive" in the studied zone and used data mining (nominal Classification method) to classify individual behavior and label them [12]. Richardson et. al. in [13] employed the two-state nonhomogeneous Markov Chain Monte Carlo (MCMC) technique to identify active and inactive users and predict the timing of the occupants' activities. Mahdavi et. al. in [14] suggested simplified and stochastic models for predicting the annual plug loads, Stochastic-Weibull distribution is used in the study and it concluded that the stochastic model performed better in predicting plug loads peak and distribution. There are several recent studies in which deep learning and machine learning techniques are employed to facilitate a better prediction, Wang Zhe et. al. in [15] and Wang Ran et. al. in [16] both used such techniques for occupancy predictions. In a wider review, Ferrantelli et. al. gathered major methods used for such modeling techniques and selected several methods in [17] that are suitable to be used in Building Performance Simulation (BPS) software; a combination of least squares regression and correlations was chosen as the best model for predicting the annual electricity use of tenants.

The increasing uncertainties in the HVAC design process will lead to excessive oversizing of the systems. A report shows that $40 \%$ of all rooftop systems are $25 \%$ oversized in California in 2000 based on peak day load design method which means that the units are radically oversized for the much of the warm season [18].

The purpose of this study is to increase the understanding of the cooling demand at the zone level (i.e. not focused on the building as a whole), by considering occupancy, window size, single / open plan office and the existence of construction parts with different thermal masses which can affect the cooling system sizing. Here the different internal heat gains models will be evaluated in order to find the best model for a reliable and optimal zonal cooling system sizing. To achieve this goal, several weekly internal heat gain profiles were selected from a large set of tenant-based electricity use measured in 4 office buildings in Tallinn. The selection was based on maximum daily or weekly peak loads of an office space per floor area. The suggested occupancy schedule by EN 16798-1, alongside the selected profiles, will be used to dimension ideal coolers in the zones of a generic floor model of a landscape office plan and variable window sizes and thermal masses of the building parts. To be able to use the suggested model in practice, the internal heat gains models resulting in the largest cooling capacity were identified.

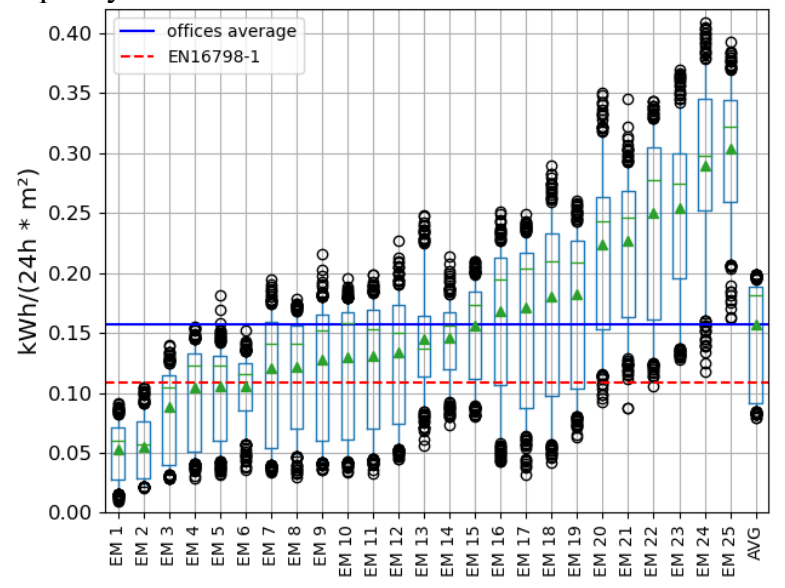

Figure 1 The distributions of data points in $\mathrm{kWh} /\left(24 \mathrm{~h} \cdot \mathrm{m}^{2}\right)$ of each measuring point in the studied building. Each EM represents a set of measured data recorded by a sensor in the numbered zone [19]. 


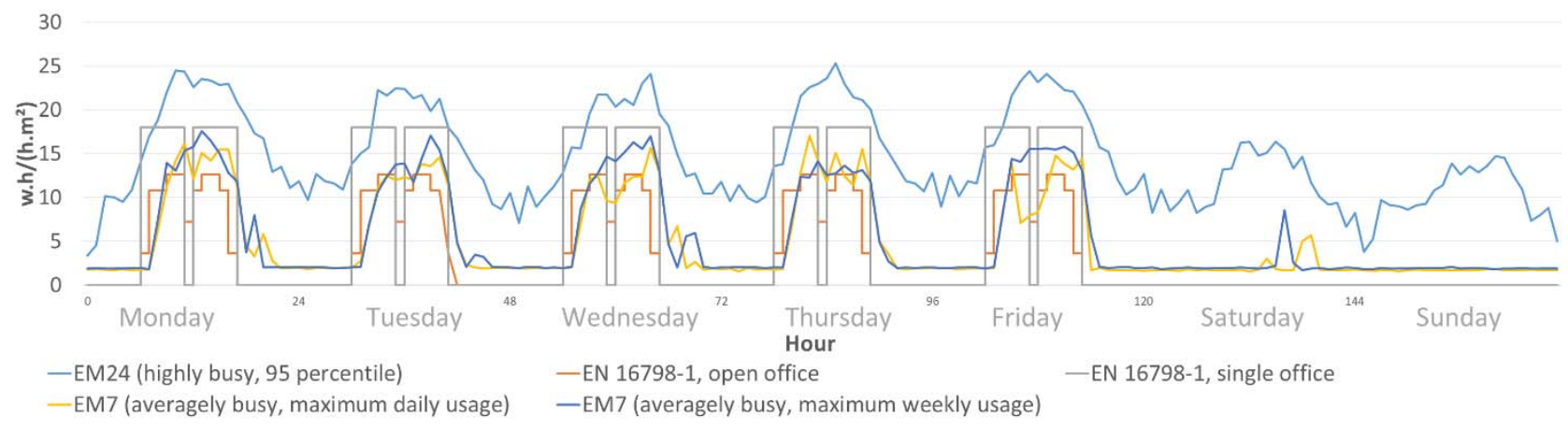

Figure 2 The weekly profiles selected for the analysis.

\section{Methods}

The experimental data used in this study were aggregated from four office buildings located in Tallinn, Estonia, from early 2017 to March 2020 (which coincided with the beginning of the COVID19 pandemic) [19]. Every building was divided into zones and electricity consumption was metered separately per each floor. Three-phase electricity meters per measurement point stored data from each building, for a period ranging between 11 and 27 months; the time resolution was one hour for two buildings and daily (24h) values for the other two. The data showed a prominent effect of the COVID19-induced lockdown after March [19].

A robust pre-processing provided data that were free from frequent stuck readings and abnormally high peaks, which were dealt with by a specific algorithm we developed to remove outliers while still keeping most of the information associated with the general trend. Figure 1 is indicating the data gathered from an office building that will be studied. The boxplot whiskers are drawn on the $5^{\text {th }}$ and $95^{\text {th }}$ percentile, triangles are the means, the blue line is the average energy consumption (plug loads and lighting) of the building and the dashed red line is representing the EN 16798-1 values [20].

As the input data of this study, we selected two measurement points in one building considering the reference daily cumulative consumption of 0.1089 $\mathrm{kWh} /\left(24 \mathrm{~h} \cdot \mathrm{m}^{2}\right)$ that is used in EN 16798-1 [20] for modeling the energy consumption (plug loads and lights) of the office buildings. The point EM7 recorded on average 0.12 , which is close to the Standard values, while EM24 displayed on average 0.28 , a substantially higher value. The raw data pertained to the period from March to September (included), when the heat gains are most problematic; from the data, a week profile with the highest cumulative daily energy usage and one with the highest cumulative weekly energy usage were selected from EM7. A weekly profile with the highest cumulative energy usage was then picked from the EM24 data to represent the crowded offices. 5 weekly profiles were selected for this study, two from EN 16798-1 and three from the studied building, as can be seen in Figure 2.
For the analysis, we have used IDA ICE 4.8 software which uses Heat Balance as the standard method for cooling design. The study is at the individual zone level, not aimed at calculating the total cooling demand. Therefore, an ideal cooler was placed in each zone to demonstrate how much heat must be removed from it.

$$
o c_{t}=\left(\frac{p l_{t}}{p l_{s}}-\frac{1.2 * p l_{\min }}{p l_{s}}\right) *\left(\frac{1}{\frac{p l_{\max }}{p l_{s}}-\frac{1.2 * p l_{\min }}{p l_{s}}}\right)
$$

The data-selected profiles were modeled as schedules for the equipment (plug loads) and lighting. The schedules for occupants were calculated based on these profiles by normalizing the values according to Formula (1), in which oc $\in[0,1]$ is the occupants' presence, $\mathrm{pl}_{\mathrm{t}}$ is the plug loads at a certain hour, $\mathrm{pl}_{\mathrm{s}}$ is the equipment and lighting consumption according to EN 16798-1 [20], $\mathrm{pl}_{\max }$ and $\mathrm{pl}_{\min }$ are the maximum and minimum consumptions recorded in the weekly profile.

The structural profiles of the same architectural plan are described in detail in the charts below. Since the purpose of the study is to compare different occupancy models and increase the understanding of cooling sizing, various profiles were selected to have low and high window-to-wall ratios and low and high thermal masses. Windows glazing is 3-pane glazing for small windows and 4-pane glazing for big windows. The window sizes are listed in Table 1, the detailed parameters in Table 2. There are two types of structural profiles of the wall, floor and ceilings with a high thermal mass difference. Design $A$ in Figure 1 has a high thermal mass in the zones by having exposed concrete, while Design B has a low thermal mass. We thus created 4 different case studies from the combination of 2 window sizes and 2 structural profiles, where hourly design profile, weekly design profile and monthly design profile were assessed. Since we targeted to analyse the impact of thermal mass and the differences between the profiles in a longer period than a design day, we edited the climate file to mimic the warmest possible climate in the simulation period. The cloudiness was $0 \%$ on all days, the data of the warmest day of each month (e.g. $15^{\text {th }}$ of June) including temperature, wind speed and radiation were copied for the whole month (e.g. June). The data for the climate file is provided in Table 3. 
Table 1. Windows sizes in the models.

\begin{tabular}{|c|c|c|}
\hline Windows group & 1 (small) & 2 (big) \\
\hline width $\mathrm{m}$ & 1.8 & 2.1 \\
\hline height $\mathrm{m}$ & 1 & 1.9 \\
\hline area & 1.8 & 3.99 \\
\hline WWR & $25 \%$ & $58 \%$ \\
\hline Total windows per office & 10 & 10 \\
\hline
\end{tabular}

Table 2. Windows glazing specifications.

\begin{tabular}{|c|c|c|}
\hline parameter & 3-pane & 4-pane \\
\hline Solar heat gain coef. (SHGC) & 0.46 & 0.37 \\
\hline T. Solar transmittance & 0.39 & 0.32 \\
\hline Visible transmittance & 0.9 & 0.9 \\
\hline Glazing U-value & 0.61 & 0.32 \\
\hline Internal emissivity & 0.89 & 0.89 \\
\hline External emissivity & 0.89 & 0.89 \\
\hline
\end{tabular}

Table 3 The climate data parameters that are constant for each month.

\begin{tabular}{|c|c|c|c|c|}
\hline parameter & June & July & August & September \\
\hline $\begin{array}{c}\text { dry bulb min } \\
\left({ }^{\circ} \mathrm{C}\right)\end{array}$ & 14 & 14 & 14 & 14 \\
\hline $\begin{array}{c}\text { dry bulb max } \\
\left({ }^{\circ} \mathrm{C}\right)\end{array}$ & 25 & 27 & 26.7 & 23 \\
\hline $\begin{array}{c}\text { wet bulb max } \\
\left({ }^{\circ} \mathrm{C}\right)\end{array}$ & 19.2 & 19.2 & 19.2 & 19.2 \\
\hline $\begin{array}{c}\text { wind speed } \\
(\mathrm{m} / \mathrm{s})\end{array}$ & 3.8 & 3.8 & 3.8 & 3.8 \\
\hline $\begin{array}{c}\text { wind direction } \\
\left({ }^{\circ}\right)\end{array}$ & 40 & 40 & 40 & 40 \\
\hline
\end{tabular}
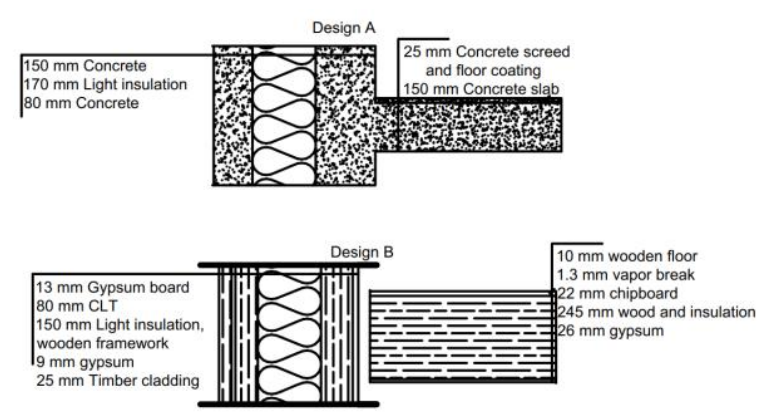

Figure 3. Structural design types of the case studies, Design A (high thermal mass) and Design B (low thermal mass).

Several assumptions have been made to facilitate the study. These assumptions were as follows:

- The number of occupants in each office was 10 , the installed power of equipment and lighting was $12 \mathrm{~W} / \mathrm{m}^{2}$ and $6 \mathrm{~W} / \mathrm{m}^{2}$ respectively,

- The supply air temperature was $18^{\circ} \mathrm{C}$,

- The offices and the staircase had a Constant Air Volume flow of $1.41 /\left(\mathrm{m}^{2 *} \mathrm{~s}\right)$,

- Shading of the windows was integrated internal blinds with sun control (never opened),
- $\quad$ Room temperature setpoint was $25^{\circ} \mathrm{C}$,

- Internal walls were the same in both heavy and light construction Design types: $100 \mathrm{~mm}$ of concrete, $30 \mathrm{~mm}$ of light insulation and $50 \mathrm{~mm}$ of gypsum with $\underline{\mathrm{U} \text {-value } 0.77 \mathrm{~W} /\left(\mathrm{m}^{2 *} \mathrm{~K}\right)}$.

In the plan, there are four different offices with the dimensions $16 \mathrm{~m} \times 8 \mathrm{~m}$, having an area of $128 \mathrm{~m}^{2}$. The height of the offices was $3 \mathrm{~m}$, which lead to $72 \mathrm{~m}^{2}$ of windowed walls. In the 3D views Figure 4 and Figure $\mathbf{5}$, the sizes and arrangements of the windows can be seen.

The office building was on the middle floor of a building, which means that the model does not have a roof connecting to the ambient air or floor slab connecting to the soil.

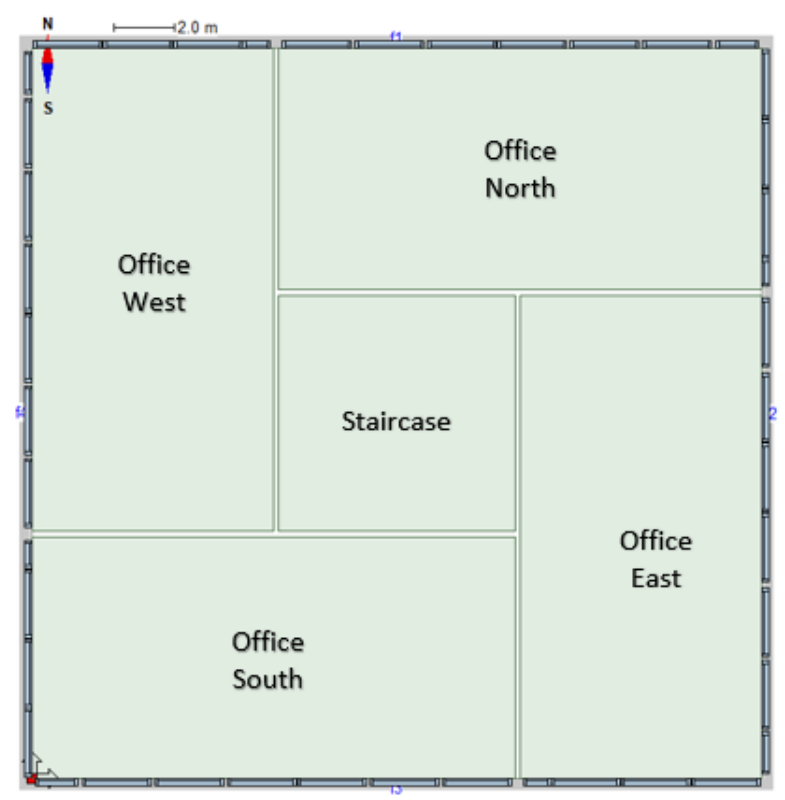

Figure 4. General office plan, $24.5 \mathrm{~m}$ x $24.5 \mathrm{~m}$

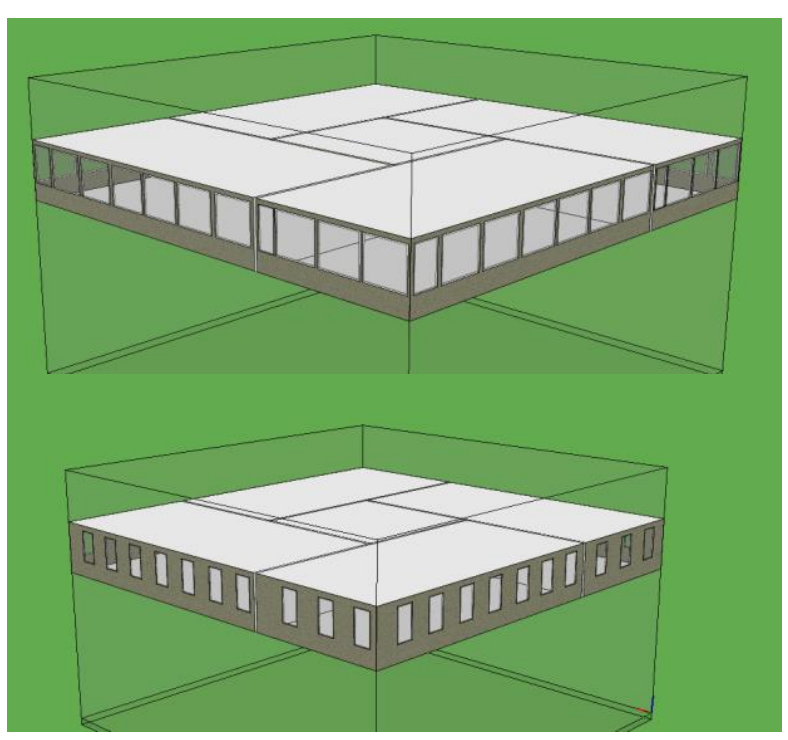

Figure 53 d of the model with 2 different Window to Wall Ratio (WWR) 


\section{Results and Discussion}

The analysis results are from simulations for a 4month period from the $1^{\text {st }}$ of June to the end of September, by using the schedules and profiles described in the previous sections. A heat balance chart from a warm week of the East office, when the profile derived from EM24 data was used, is shown in Figure 6. The building was modeled according to the design B (light construction) with big windows. This combination resulted in the highest cooling capacity needed among 80 possible combinations. From the heat balance chart, the reader can realize that the internal blinds of the windows are limiting the direct sunlight (yellow), but the heat from windows and absorbed heat in the internal blinds (light blue color with peaks) are the biggest contributors to the warm indoor air. The internal heat gains are the second contributors, then heat from occupants and equipment.

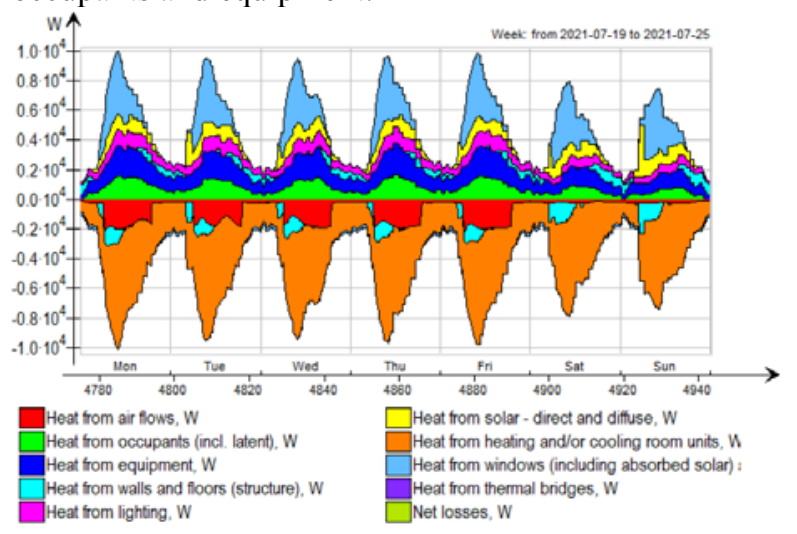

Figure 6 Heat Balance chart of a warm week for the East office, EM24 profile, light construction and big windows

A summary of all the simulations is shown in Figure 7. The South and East offices need a bigger cooling system per square meter compared to the Northern and Western offices. The effect of having a heavy structure (in this study, exposed interior concrete wall and floor) is positive, leading to lower cooling system size. The reason behind this reduction is the thermal mass of the building structure which works as a regulator of the indoor air temperature by keeping the coldness of the weather during less occupied hours and releasing it during the warm periods. The size of the windows is also influencing the results: the bigger the window, the bigger the size of the cooling system. From the heat balance chart, Figure 6, we see that the sun heat is controlled by using internal blinds, so the heat which transfers through windows became important, thus forcing the designers to choose bigger cooling systems.

The simulations based on the busy profile, EM24, resulted in much bigger cooling systems compared to average profiles from EM7 and the profiles from EN 16798-1. In practice, practitioners usually use a set of assumptions for occupancy and may use the suggestions of the EN 16798-1 standard. For busier offices that are overcrowded according to the original design, these assumptions and suggestions can become problematic, leading to either forced movements between offices or low users' satisfaction. On average, window size change from Window to Wall Ratio (WWR) $25 \%$ to $58 \%$ resulted in 35\% bigger cooling systems; besides, having the thermal mass of the heavy structure in the zones can reduce the size of the cooling systems by $7 \%$ on average.

The differences between the size of the cooling system for different occupancy/equipment profiles for the Northern office are visible in Figure 8. The reader can see that the significance of differences among the results of the simulations with the EN 16798-1 suggested values depends on the profiles that are selected. While the difference is not significant if the results are compared to the average results of the EM profiles together, it is significant indeed compared to each individual profile. Since all three EM profiles are taken from the actual offices, it is important to consider such gaps and try to fill them when designing office buildings.

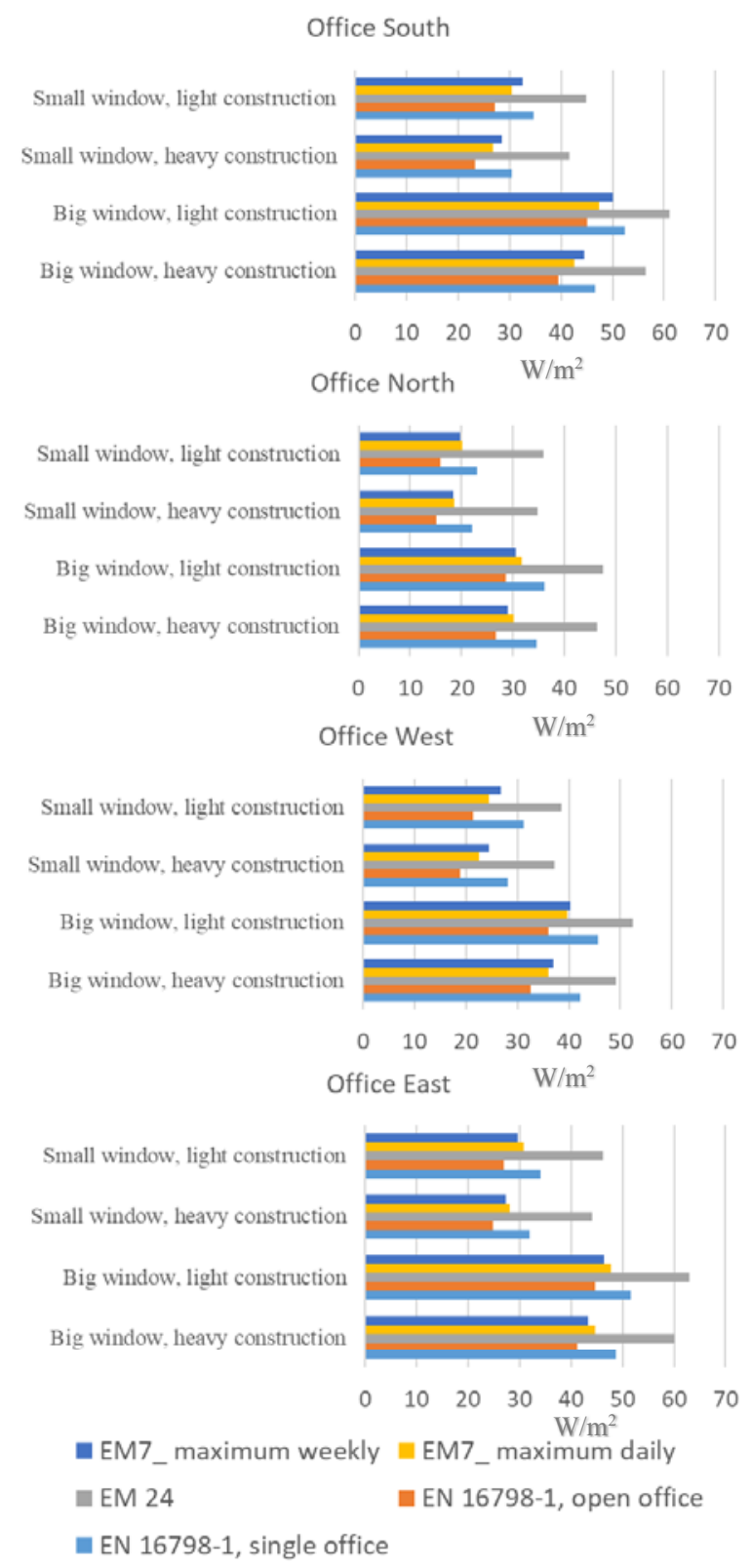

Figure 7 Cooling system size drawn using the results of the simulations for different scenarios/offices 
As we can see in Figure 7 and Figure 8, the profiles suggested by the EN 16798-1 standard are not satisfactory in some situations, Therefore the designers need to understand the functionality of the zones and predict the internal heat gains of different zones carefully. A thorough study on profiles can lead to specific profiles that can be suggested for specific offices in a defined location in the future.

We also should remark again that the present study concerns only a zonal analysis. At the full-building scale the assessment becomes more involved since the cooling demand is also linked with de-humidification of supply air flow rate while there is a potential to use Renewable Energy Sources (RES) to cover a part of the cooling demand.

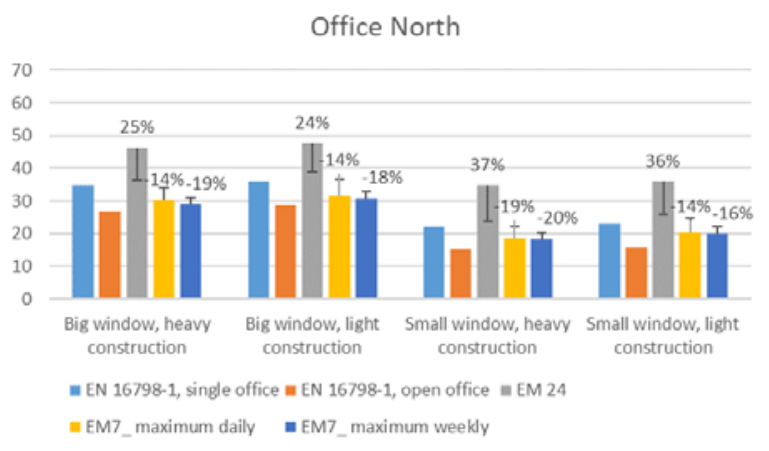

Figure 8 The cooling system size for the Northern office, magnifying the differences between profiles and EN 16798-1 suggestion.

Recalling our measured data, the blue line in Figure $\mathbf{1}$ is the average consumption in the building. This line can be a good reference for dimensioning the cooling system of the whole building, while dimensioning the individual cooling devices in each zone needs a specific profile for that zone. Using the EN 16798-1 suggestion is good to start with, however being able to predict the profiles using smarter methods will lead to more efficient cooling device installation and cooling systems.

In this study, we calculated the total cooling demand of each zone. In reality, there is a huge potential in utilizing the free cooling concept in cold climates to reduce the cooling demand. This means that by using only the external air temperature, we will be able to cool the indoor environment down without consuming energy for cooling devices.

To do a brief sensitivity analysis, we decided to use the maximum cooling capacity sizes that were calculated using the EM7 profiles for simulating based on the EM24 profiles. A model is developed with constant cooling capacity for ideal coolers in 4 different offices derived from simulations of EM7 profiles, to report the mean temperature of the offices during the simulation period. The duration curve of the four offices is shown in Figure 9. From the figure, we can see that nearly one-third of the hours in the simulation period have a mean temperature higher than the set point.
Detailed analysis and specific studies on such cases can be done in a separate paper in the future.

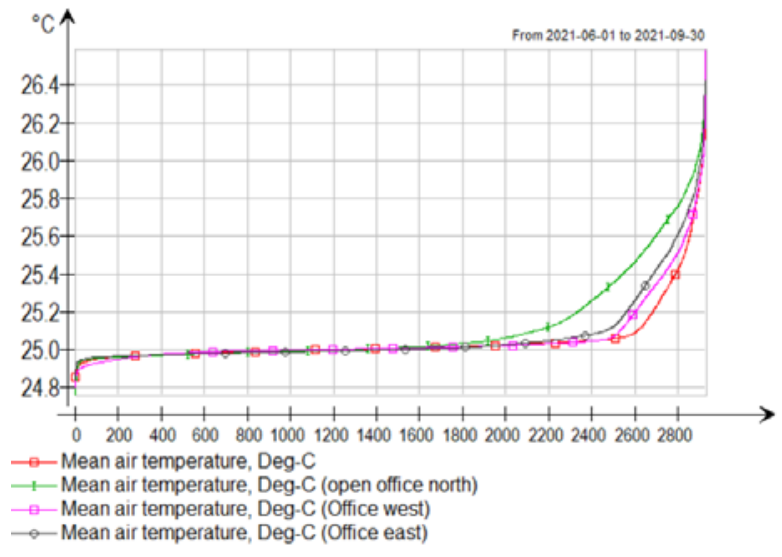

Figure 9 Duration Curve for 4 offices in a building with heavy construction, big windows and EM24 profile while the cooling capacity o ideal coolers are set to be equal to the designed values with EM7 profile.

\section{Conclusion}

Due to the climate change, the modeling of buildings for the warm periods and cooling system design are becoming more and more needed, especially in the Northern region of the EU. While nowadays designers are incorporating sustainable façade design which increases the internal heat gain impact on the cooling system, the results of this study show the importance of predicting the internal heat gains with as low margins as possible during the design stage. Having in mind the heat gain through windows is also another factor toward a successful cooling system design.

In the future, a more in-depth data analysis to suggest a better profile for the specific area than the standard EN 16798-1 can be a positive contribution, since such suggestions can be tested and compared to make the suggested profile even smoother.

The impact of thermal mass can be investigated in detail, using a profile with low occupancy and a profile with high occupancy, to check how much occupancy will make a difference in cooling system sizing.

\section{Acknowledgement}

This research was supported by the Estonian Centre of Excellence in Zero Energy and Resource Efficient Smart Buildings and Districts, ZEBE (grant 20142020.4.01.15-0016) funded by the European Regional Development Fund, by the European Commission through the H2020 project Finest Twins (grant No. 856602) and the Estonian Research Council grant (PSG409).

\section{References}

[1] A. Eleonora, M. Frey and F. Rizzi, "Towards nearly zero-energy buildings: The state-of-art 
of national regulations in Europe," Energy, vol. 57, pp. 125-133, 2013.

[2] J. Oh, T. Hong, H. Kim, J. An, K. Jeong and C. Koo, "Advanced Strategies for Net-Zero Energy Building: Focused on the Early Phase and Usage Phase of a Building's Life Cycle," Sustainability, vol. 12, p. 2272, 2017.

[3] D. P. Jenkins, "The importance of office internal heatgains in reducing cooling loads in achanging climate," Low-Carbon Technologies, vol. 4, pp. 134-140, 2009.

[4] T. Coşkun, C. Turhan, Z. Durmuş Arsan and G. Gökçen Akkurt, "The Importance of Internal Heat Gains for Building Cooling Design," Thermal Engineering, vol. 3, pp. 1060-1064, 2017.

[5] F. Goia, "Search for the optimal window-towall ratio in office buildings in different European climates and the implications on total energy saving potential," Solar Energy, vol. 132, pp. 467-492, 2016.

[6] M. Thalfeldt, E. Pikas, J. Kurnitski and H. Voll, "Facade design principles for nearly zero energy buildings in a cold climate," Energy and Buildings, vol. 67, pp. 309-321, 2013.

[7] M. Thalfeldt and J. Kurnitski, "External shading optimal control macros for 1- and 2piece automated blinds in European climates," Building Simulation, vol. 8, pp. 13 - 25, 2015.

[8] I. Sarbu and C. Sebarchievici, "A Comprehensive Review of Thermal Energy Storage," Sustainability, vol. 10, no. 1, p. 191, 2018.

[9] B. He, "High-Capacity cool thermal energy storage for peak shaving - a solution for energy challanges in the 21 st Century," Stockholm, 2004.

[10] American Society of Heating, Refrigerating and Air-Conditioning Engineers, Inc., ASHRAE® Handbook - Fundamentals (SI Edition) - 18.6.2 Overview, American Society of Heating, Refrigerating and AirConditioning Engineers, Inc. (ASHRAE), 2017, pp. 57, 58.

[11] V. W. Y. Tam, L. Almeida and K. Le, "Energy-Related Occupant Behaviour and Its Implications in Energy Use: A Chronological Review," Sustainability, vol. 10, no. 8, p. 2635, 2018.

[12] J. Zhao, B. Lasternas, K. P. Lam, R. Yun and V. Loftness, "Occupant behavior and schedule modeling for building energy simulation through office appliance power consumption data mining," Energy and Buildings, vol. 82, pp. 341-355, 2014.
[13] I. Richardson, M. Thomson and D. Infield, “A high-resolution domestic building occupancy model for energy demand simulations," Energy and Buildings, vol. 40, no. 8, pp. 15601566, 2008.

[14] A. Mahdavi, F. Tahmasebi and M. Kayalar, "Prediction of plug loads in office buildings: Simplified and probabilistic methods," Energy and Buildings, vol. 129, pp. 322-329, 2016.

[15] Z. Wang, T. Hong and M. A. Piette, "Data fusion in predicting internal heat gains for office buildings through a deep learning approach," Applied Energy, vol. 240, pp. 386398, 2019.

[16] R. Wang, S. Lu and W. Feng, "A novel improved model for building energy consumption prediction based on model integration," Applied Energy, vol. 262, p. 114561, 2020.

[17] A. Ferrantelli, H. Kuivjõgi, J. Kurnitski and M. Thalfeldt, "Office Building Tenants' Electricity Use Model for Building Performance Simulations," Energies, vol. 13, no. 21, p. 5541, 2020.

[18] D. R. Felts and P. Bailey, "The state of affairs-packaged cooling equipment in California," Proceedings of the 2000 ACEEE Summer Study on Energy Efficiency in Buildings, pp. 137-147, 2000.

[19] A. Ferrantelli, H. K. Aljas, V. Maask and M. Thalfeldt, "Tenant-based measured electricity use in 4 large office buildings in Tallinn, Estonia," in Cold Climate HVAC 2021, Tallinn, 2021.

[20] EN 16798-1, "Energy performance of buildings - Part 1: Indoor environmental input parameters for design and assessment of energy performance of buildings," CEN, Brussels, Belgium, 2019. 